Grampian introduced new AWI Section 47 documentation and its use was audited in an acute palliative care unit.

Methods Data was collected from all in-patients in an acute palliative care unit over a 1 week period. Information was collected on four domains:

- was an AWI certificate present in the medical notes,

- was the decision to complete an AWI certificate documented in the medical notes (including the reasons for this decision),

- was the AWI certificate completed correctly,

- was there documentation of a discussion with Welfare Power of Attorney or next of kin regarding the decision to complete an AWI certificate.

Results Data was collected on 16 in-patients, 8 male and 8 female, mean age 71 years.

- $31 \%$ had an AWI certificate completed.

- AWI certificate completed correctly in all cases.

- 1 patient had documentation of an assessment of capacity/ completion of AWI certificate recorded in medical notes.

- 2 patients had documentation of discussion with Welfare Power of Attorney/next of kin.

Conclusions The proportion of patients with an AWI Section 47 certificate is in keeping with the prevalence of delirium in medical wards. There was good compliance with completion of the new AWI Section 47 certificates. Documentation of assessment of capacity/decision making and discussion with relevant others was lacking - these are important principles of the act and further education and training should address these areas.

\section{P-46 ORTHOSTATIC HYPOTENSION AND HEART RATE VARIABILITY IN THE DIAGNOSIS OF AUTONOMIC DYSFUNCTION IN ADVANCED CANCER}

${ }^{1}$ Chang Sheng Leong, ${ }^{2,3}$ Michelle Barrett, ${ }^{1,3}$ David Joyce, ${ }^{1,2,3}$ Declan Walsh. ${ }^{1}$ University College Dublin, Belfield, Ireland; ${ }^{2}$ Trinity College Dublin, Ireland; ${ }^{3}$ Our Lady's Hospice, Care Services, Ireland

\subsection{6/bmjspcare-2017-00133.46}

Background Autonomic dysfunction (AD) is common in advanced cancer. Cardiovascular signs include loss of heart rate variability (HRV) and later, orthostatic hypotension $(\mathrm{OH})$. $\mathrm{OH}$ increases risk of falls and mortality. HRV is the time difference between successive heartbeats, measured as a standard deviation (SDNN). The mean SDNN found in normative population is $41.51 \mathrm{~ms}(\sigma: 26.28 \mathrm{~ms})$. $\mathrm{OH}$ is a decrease of $\geq$ $20 \mathrm{mHg}$ in systolic and/or $10 \mathrm{mHg}$ in diastolic blood pressure (BP) upon orthostatic stress. Persistence of $\mathrm{OH}(\mathrm{POH})$ is $\mathrm{OH}$ beyond three minutes

Methods This prospective, observational study aimed to identify prevalence of $\mathrm{OH}$ and $\mathrm{POH}$, examine the relationship between autonomic symptoms (AS) and $\mathrm{OH}$, and to ascertain whether $\mathrm{OH}$ and HRV are equivocally reliable for AD diagnosis. Consecutive ambulant adults attending day or in-patient hospice services were recruited. Interviews established demographics and AS. Objective tests for HRV and BP measurement were conducted. Postural symptoms were recorded during testing.

Results 22 (12 male, 10 female) participants were recruited. Median age was 70 (33-89). Eight had $\mathrm{OH}$, three of these had $\mathrm{POH}$. None with $\mathrm{OH}$ reported postural symptoms. Mean number of AS reported in non-POH group $(n=5)$ and $\mathrm{POH}$ group $(n=3)$ was $8 \quad(\sigma: 2.55)$ and $12(\sigma: 1.73)$ respectively. Mean SDNN $(n=20)$ was $25.53 \mathrm{~ms}(\sigma: 17.55 \mathrm{~ms})$. Association between $\mathrm{OH}$ and HRV ( $\mathrm{p}=0.048$, unpaired $\mathrm{t}$ test).

Conclusions $\mathrm{OH}$ was prevalent in this advanced cancer cohort and was associated with increased HRV. No association was found between AS and $\mathrm{OH}$. Therefore, AS profile was not a useful tool for assessing AD. Active stand test was tolerated by all participants and could be considered for routine screening in advanced cancer. HRV screening may be an alternative for frailer patients

\section{P-47 A QUALITY IMPROVEMENT APPROACH TO COGNITIVE ASSESSMENT ON HOSPICE ADMISSION: COULD WE USE THE 4AT OR SHORT CAM?}

Lucy Baird, Juliet Spiller. Marie Curie Hospice, Edinburgh, Scotland

\subsection{6/bmjspcare-2017-00133.47}

Background Prevalence studies show that 15\%-42\% of patients admitted to specialist palliative care inpatient units have delirium. Symptoms of delirium are often subtle and easily missed, or misdiagnosed as fatigue or even depression, and so the use of a screening tool could improve early identification and management of delirium and lead to improved outcomes. Patients admitted to the hospice are often frail and tired, therefore a quick and easy-to-use method of cognitive assessment is essential.

Methods A quality improvement (QI) approach (PDSA: Plan, Do, Study, Act) was used to improve screening for delirium on admission to a hospice unit. A baseline measure was taken of the rate of performing cognitive assessment on admission. Five PDSA cycles were then undertaken which involved implementing change and then evaluating results through auditing case-notes and interviewing staff.

Results The first cycle determined staff preference between the Short CAM and the 4AT. Two further PDSA cycles embedded the 4AT (the preferred tool) into the admission process, establishing it as a usable tool in the hospice setting for up to 92\% of admissions. A subsequent cycle showing poor sustainability prompted further improvements to staff education and changes to admission documentation.

Conclusions The 4AT is a usable tool in the hospice inpatient setting to assess patients' cognitive state on admission, and can easily be incorporated into the admission process. The QI approach highlighted the need to link staff awareness of their use of the screening tool with perceived improvements in the treatment of delirium, which prompted the creation and implementation of a delirium checklist in the unit. Some lack of sustainability of the initial improvement was addressed by staff education and changes to the admission paperwork to ensure compliance with the use of the 4AT and sustained improvement in screening for cognitive impairment on admission.

\section{P-48 ANTIMICROBIALS IN END OF LIFE CARE: AN AUDIT AT THE ROYAL TRINITY HOSPICE}

Eleanor De Rosa, Barbara Sheehy-Skeffington. Royal Trinity Hospice, London, England.

10.1136/bmjspcare-2017-00133.48 